\title{
A história da Colônia de Ivoti - uma entrevista
}

\author{
Jobannes Doll
}

\section{Introdução}

No contexto da imigração japonesa no sul do Brasil, a colônia de Ivoti ganhou uma importância especial, pois se trata da primeira experiência considerada bem-sucedida de uma colônia japonesa no Rio Grande do Sul. As suas origens remetem aos anos 60 , portanto já há quase 40 anos. Hoje, os primeiros moradores estão ficando velhos, já existe uma segunda e até uma terceira geração. Para a histónia do processo de colonização, trata-se de um momento decisivo, mister agora registrar os inícios desta colônia, enquanto os primeiros moradores ainda estão vivos. Não aproveitando deste momento, as ricas memórias da primeira fase da fundação desta colônia iria se perder.

Cabe realizar uma curta referência ao conceito de memória aqui usada. Apesar dos interesses na reconstrução do que aconteceu 40 anos atrás, temos que estar conscientes de que as memórias das pessoas não representam uma "fotografia objetiva" dos acontecimentos naquela época, mas uma narrativa que se constituiu durante todos estes anos. Neste sentido, a memória dos primeiros moradores da colônia de Ivoti traz menos e/ou mais informações do que um registro objetivo poderia dar: menos, no sentido de que algumas informações e alguns detalhes podem-se ter perdidos durante os anos ou ter recebido reformulações alterando o que, de fato, aconteceu. Mas estes relatos trazem, por outro lado, muito mais, pois representam uma interpretação dos fatos e uma atribuição de significados aos acontecimentos passados, que nos permitem uma compreensão melhor do processo histórico da fundação e do desenvolvimento da Colônia de Ivoti. Esta concepção de memótia encontra seu fundamento na obra de Ecléa Bosi, onde ela reconstrui uma parte da história de São Paulo a partir de entrevistas com velhos moradores. A respeito da questão da veracidade das informações recebidas, Bosi aponta o seguinte:

"Não dispomos de nenhum documento de confronto dos fatos relatados que pudesse servir de modelo, a partir do qual se analisassem distorgões e lacunas. Os livros de história que registram esses fatos são também um ponto de vista, uma versão do acontecido, não raro desmentidos por outras livros com outros pontos de vista. A veracidade do narrador não nos preocupou: com certeza seus erros e lapsos são menos graves em stas consequiências 
que as omissöer da bistoria oficial. Nosso interesse está no que foi lembrado, no que foi escolbido para perpetuar-se na história de sua vida. Recolbi aquela "evocasäo en disciplina" que chamei de memória-trabalho." (Bosi 1994, p. 37).

Um outro aspecto importante destas memórias é que não são simplesmente algo individual, mas são guardadas em um contexto social. Como demonstra a pesquisa de Cornelia Eckert (1993), estas memórias desenvolvidas e guardadas nas interações sociais de um determinado grupo representam elementos constitutivos da identidade deste grupo. Neste sentido, a entrevista relatada em seguida, traz elementos importantes do passado, mas mais do que isso, ela possui um lugar social dentro da comunidade da Colônia, fala-nos das perspectivas e dos sonhos dos primeiros moradores da Colônia Japonesa de Ivoti e permite perceber traços importantes da identidade das pessoas que vivem neste espaço específico.

No contexto da nossa pesquisa "Imigtação e Envelhecimento" realizamos em agosto de 2002 uma entrevista com o Senhor Sasada, o primeiro morador da comunidade de Ivoti, que teve uma função importante junto a comunidade, já que ele é formado em agronomia e, portanto, conhecedor do assunto que representa a base econômica da Colónia. O que segue não é uma transcrição da entrevista, que foi realizada em japonês, com tradução para o português, mas anotações a partir das informações que o Senhor Sasada nos passou.

\section{A entrevista}

A casa do casal, onde foi realizada a entrevista, é situada no meio de laranjeiras. $O$ interior da casa é bem arrumada e encontram-se muitas lembranças do Japão, como fotos da família, bonecas, uma coleção de armas de kendo, uma foto do Senhor Sasado vestido com a roupa tradicional de luta de kendo e um armário de vidro onde são guardados outras lembranças.

O Senhor Sasado informa-nos que ele com sua esposa e os três filhos chegaram no Brasil depois da Segunda Guerra, em 1959. Eles já foram a segunda geração de imigranres japoneses no Brasil. Na época, o Japão enfrentava ainda problemas sétios do pós-guerra e eles buscaram algo novo no mundo novo. Nesta época aumentou a quantidade de imigrantes japoneses no sul, eles plantaram tomates e verduras, o que deu um bom lucro. Mas o mercado ficou saturado e surgiram problemas financeiros, o dinheiro que tinham trazido do Japão acabou. Assim, eles procurararn mudar de atividades e discutiram outras idéias, como a plantação de flotes, de arroz, de frutas ou a criação de aves. A primeira idéia foi o plantio de frutíferas, mas eles não tinham terra própria. Arrendar, por outro lado, não valia a pena, pois as árvores demoram para dar lucro. Assim, eles resolveram que teriam que adquirir terra própria. Para conseguir as verbas, eles negociaram com o governo japonês um empréstimo a médio prazo. O próximo passo era achar um terreno adequado. Eles procuratam por

1 Geração neste lugar quer dizer, segunda leva de imigrantes, pois os imigrantes japoneses se dividem na primeira leva, antes da Segunda Guerra Mundial, e na segunda leva, após a Guerra. 
quatro anos em vários lugares. Em Caxias, tinha terra propícia para arvores frutíferas, mas a idéia não se realizou. No meio tempo, um Senhor de Yvoti apresentou um terreno de Ivoti e convidou-os para conhecer. Eles olharam, gostaram e resolveram adquirir. Isso foi 40 anos atrás, nos anos 60 .

Nesta ocasião vieram 26 familias japonesas. Eles foram definir qual planta seria adotada e decidiram-se pela uva italiana. No total eram 120 hectares para 26 famflias. Desta forma, cada familia ficava com mais ou menos cinco hectares aráveis. Depois de três anos, tinham o primeiro plantio, a primeira exportação foi para São Paulo. Ele considera que Ivoti foi uma boa escolha, pois fica perto da capital, de Porto Alegre (em torno de $50 \mathrm{~km}$ ) e perto de grandes hospitais. Eles se preocupavam muito com a educação dos filhos e em Ivoti existiam boas escolas.

O maior problema foi a falta de água neste lugar. Assim, eles resolveram ativar um projeto que Ivoti já tinha e adquiriram uma cascata de Dois Irmãos. Desta cascata fizeram um canal de abastecimento, mas não era suficiente. A água encontravà-se em um nivel mais baixo. Para alcançar seus objetivos, eles tiveram que fazer uma represa e adquirit uma bomba que levanta a água por 60 metros. Este empreendimento foi realizado com verbas do JAMIC (Japan Migration Company). Mas para acionar a bomba de água, foi necessária a instalação de fiação elétrica. Eles procuraram a empresa para financiar a obra e fizeram um projeto com o governo japonês. Segundo ele, isso foi a primeira liberação de verbas que o governo japonês fez para um projeto deste tipo. Para a construção da represa, foi adquirida terra com dinheiro do JAMIC, também houve ajuda financeira através do BRDE (Banco Regional do Desenvolvimento Econômico). Como eles estavam adquirindo mais terra, convidaram outras famillias japonesas para se instalarem também na colonnia. Além destas ajudas financeiras, eles receberam 20.000 cruzeiros por família para a criação de frangos. Também precisavam pegar outros pequenos empréstimos com bancos. Para administrar melhor a produção e a venda dos seus produros, eles fundaram uma cooperativa, o que ajudou a saldar todo o débito. Com a JAMIC, eles precisavam devolver somente uma parte do dinheiro. No total, demorou 18 anos até eles conseguiram quitar toda a divida. Ele ficou muito contente pelo fato que eles conseguiram devolver todo o dinheiro.

A represa funciona até hoje, são duas bombas de $80 \mathrm{HP}$ e toda hora tem água potável. Muitas casas não têm um poço próprio e dependem do sistema de água que eles construiram. Na verdade, são dois sistemas de distribuição com dois graus de filtros. Um serve para a irrigação das plantas, é um sistema com 20 polegadas, e a água vem diretamente do rio. O outro, um sistema menor com 3 a 4 polegadas, possui um sistema de filtros e serve para a água potável. Este sistema é independente do sistema de distribuição de água de Ivoti. Dentro da comunidade existe sempre uma pessoa que é responsável para a manutenção do sistema de água, esta pessoa é escolhida em assembléia. As pessoas pagam mais ou menos 30 reais para a água. Existe um contador para a água porável, para a água de irrigação paga-se uma taxa fixa.

Uma das condiçōes para se instalar na colônia era a produção de uvas de qualquer tipo. No restante do terreno, cada um poderia plantar o que queria. As pessoas plantaram caqui, laranja e pêssego. Quando a colônia foi fundada, a média de idade dos país de família 
eta de vinte e poucos anos, ele era o mais velho, já tinha 40 anos. Hoje, ele tem 84 anos e os outros têm 60 anos.

Além da uva plantou-se também outras plantas, mas uva era o que mais deu na região. Mas o cultivo de uva de mesa é difícil, depois o preço caiu. Usou-se muito agrotóxico, o que é muito perigoso, especialmente o manejo da aplicação. Um problema é que quando se aplica o agrotóxico e depois chove, tem que aplicar de novo. Hoje, as pessoas estão envelhecendo e, com a idade, tudo isso fica mais dificil. Ele mesmo não continuou. Ele tem uma renda minima necessária; isso dá para sobreviver; ele não trabalha mais muito. As crianças, em geral, estudam, têm escolaridade maior e querem ir para a cidade. O que afetou também bastante a colônia é o dekassegui, o sistema de trabalho temporário no Japão que atrai muitos jovens pela possibilidade de se ganhar dinheito. Entre os membros da comunidade, existem hoje alguns que são bons produtores, ganham muito bem e os filhos deles foram à universidade. Em relação à comunidade, ele era o mais velho, mas não era presidente: ele era o vice. $O$ presidente foi amigo dele, mais tarde sofreu um acidente de trânsito. Mas eles decidiram sempre tudo em assembléias e todo mundo participou. O mais dificil foi devolver o dinheiro, mas, graças a Deus, eles estâo hoje deste jeito. Com a comunidade de Ivoti sempre tiveram boas relações; a população de Ivoti também ajudou eles a devolverem o dinheiro aos bancos.

Em relação à saúde, eles têm poucos acidentes de trânsito aqui. Antigamente, bebiase muito e se fumava muito. Beber era com os amigos. Mas muitas pessoas pararan de bebet por causa de problemas com a saúde. Existem alguns casos de câncer de fígado. Hoje são, no total, mais ou menos 40 famílias.

Perguntado sobre como foi o início aqui na colônia, ele conta que teve um sorteio no escritório da JAMICA; foram sorteados os lotes da colônia. Houve dois sorteios. Ele ganhou o lote 25. No mesmo dia, ele foi ver o lote e gostou. Ele voltou ao seu galpão em Estância Grande, distrito Viamão, desmanchou o galpão e colocou tudo num caminhão para vir a Ivoti. No caminho, o caminhão quebrou, então ele foi deixado na estrada. Teve que contratat outro caminhão e finalmente cbegou em Ivoti para construir sua casa aqui. Ele foi o primeiro morador na colônia, depois chegaram outros, e ele ajudou aqueles que estavam chegando. Isso foi em 1966.

Perguntado sobre a escola, ele explicou que todos foram para a escola. Quando o governador perguntou a eles o que a colônia precisava, eles pediram uma escola. Ela foi construída ao lado da cooperativa. Atualmente ela está desativada, pois não têm mais muitas crianças na colônia, mas pode ser ativada a qualquer momento. A professora era de Ivoti, de origem alemã. As crianças aprenderam o português na escola, pois os pais falavam japonês. Mas, como a professora era de origem alemã, as crianças japonesas aprendetam o português com sotaque alemão. Isso eles perceberam somente depois, quando falavam com outras pessoas de fora de Ivoti.

Ele conta ainda que, quando era jovem e estudava agronomia na Faculdade em Japão, ele lutava kendo como esporte. Agora, um parente mandou do Japão um conjunto de trajes de kendo, o qual ele vestia para uma foto (mostrando a foto). Mas hoje ele acha a armadura muito pesada. 


\section{Observações finais}

A descrição da entrevista mantém a estrutura e o ritmo dos temas abordadas pelo senhor Sasada. Percebe-se que certos elementos voltam a ser abordados, são aprofundados e complementados. A entrevista traz uma imagem viva da situação dos imigrantes japoneses nos anos 60 , quando eles procuraram um espaço e um lugar na sociedade rio-grandense. A questão de ter um lugar próptio, um pedaço de terra seu, parece interessante e significativo. $O$ senhor Sasada tinha estudado agronomia, isso explica o interesse de ganhar sua vida na área da agricultura. Mas a vontade de ser dono de um pedaço de terra possui um significado maior. Por um lado, pode ser explicado pela falta de espaço no seu país de origem Japão, onde a posse de terra é algo muito valioso, já que existe pouco espaço para tantas pessoas. Isso pode explicar também o contenramento com as parcelas relativamenre pequenas de cinco hectares, o que, em termos getais do Rio Grande do Sul, é muito pouco para garantir o sustento de uma família. Um outro aspecto interessante de se tornarem proprietários é o seu caráter definitivo. Enquanto os primeiros imigrantes japoneses no Rio Grande do Sul, ainda antes da Segunda Guerra, chegatam com o objetivo de ganhar muito dinheiro em pouco tempo para poder voltar para o Japão e, em função disso, não compraram, mas arrendaram a terra, os moradotes da Colônia de Ivoti chegaram para ficar. Neste sentido, a aquisição de um pedaço de terra representa uma decisão definitiva de querer estabelecet-se neste país, de querer ficar. A força deste desejo fica ainda mais evidente pensando nas dificuldades que eles tiveram que enfrentar.

Isso leva a um segundo tema que é retomado várias vezes, a questão da água. Percebe-se desta forma, mas também pela descrição detalhada das soluções encontradas, a importância deste assunto para a vida da colônia. Em primeiro lugar, trata»se de uma questão econômica, pois sem a água não há como plantar o tipo de fruta adequada que pode garantir o sustento, a uva de mesa. Por outro lado, as próprias pessoas precisam a água para viver. Mas de novo, a importância da água vai além da sua funcionalidade, pois ela representa até hoje um dos fundamentos da organização da própria colônia. Na situação encontrada com a falta de água, uma solução individual não era possivel, pois precisava-se da força de uma comunidade para adquirir uma cascata, para construir uma represa, para instalar un sistema de distribuição de água e para conseguir dinheiro para financiar tudo isso. Desta maneira, o sistema de água exige a organização de uma comunidade; por outro lado, a própria construção somente era possível por um grupo de pessoas dispostas a investir em um bem comum. Desta forma, a existência da água hoje na colônia represenra o sucesso de um esforço conjunto.

Finalmente, podemos observar o contentamento do senhor Sasada também presente em vários momentos da entrevista. O que mais chama a atenção é a satis fação de ter saldado toda a dívida que eles tiveram que contrair para financiar o projeto da Colônia de Ivoti, ptincipalmente a infra-estrutura. Esta primeira geração dos moradores da Colônia Japonesa de Ivoti conseguiu, de forma coletiva, alcançar os seus objetivos: adquirir um pedaço de terra e construir uma infra-estrutura que permite que eles consigam viver bem neste seu novo país. Enquanto uma grande parte dos outros membros desta primeira geração ainda estão ativos, o senhor Sasada, por ser o mais velho, já se retirou da vida profissional ativa. Em 
relação a isso, até a história do esporte que ele praticava, o kendo, ganha um valor simbólico. Ele tinha praticado este esporte marcial quando estudante c, quando adulto, ele teve que lutar bastante para conseguir realizar seus objetivos. Agora que cle vestiu a armadura de novo, the parecia muito pesada. De certa forma, ele não precisa mais da luta que marcou sua vida: ele alcançou seus objetivos.

\section{REFERÊNCIAS BIBLIOGRÁFICAS}

BOSI, Ecléa. Memória e Sociedade. Lembranças de Velhos. $3^{a}$ ed. São Paulo: Companhia das Letras, 1994.

ECKERT, Cornelia. Memória e Identidade. Ritmós e ressonância da duração de uma comunidade de trabalho: mineiros do carvão (La Grand-Combe, França). Cadernos de Antropologia, $n^{\circ} 11,1993$. 